\title{
CONSUMO E CUSTO DA ALIMENTAÇÃO PARA RECUPERAÇÃO DAATIVIDADE OVARIANA LUTEAL CÍCLICA DE VACAS MESTIÇAS LEITEIRAS COM ANESTRO'1
}

\author{
ADEMIR DE MORAES FERREIRA ${ }^{2}$, CIRO ALEXANDREALVES TORRES ${ }^{3}$, WANDERLEI FERREIRADE SÁ ${ }^{2}$ \\ e JOÃO HENRIQUE MOREIRA VIANA ${ }^{4}$
}

\begin{abstract}
RESUMO - O objetivo do trabalho foi verificar o consumo e o custo de alimentos para recuperação da atividade ovariana luteal cíclica (AOLC) em vacas mestiças Holandês x Zebu com anestro. Foram usadas 18 vacas, não-gestantes, não-lactantes, magras, apresentando ovários sem função luteal, de tamanho normal e sem folículos palpáveis na superfície. Doze animais permaneceram em confinamento e receberam alimentação para ganho de peso até o reinício da AOLC. Os seis animais restantes, constituindo o grupo controle, receberam alimentação de mantença para o baixo peso apresentado e permaneceram em anestro durante o período experimental. A AOLC foi avaliada pela concentração de progesterona no soro sangüíneo (coleta de sangue a cada sete dias), pelo exame dos ovários por palpação retal a cada 12 dias, e observação visual dos sinais do estro três vezes ao dia. A recuperação da AOLC nas vacas com anestro exigiu um consumo médio de 722,4 kg de matéria seca, 50,4 kg de proteína bruta e 402,4 kg de NDT, relativos à ingestão média de 2.374,2 kg de volumoso e 194,1 kg de concentrado. O custo desses alimentos somado à perda estimada da produção de leite numa vaca de 3.000 litros de leite/lactação, provocada pelo prolongamento do intervalo de partos, foi equivalente a $1.364,2$ litros de leite (preço recebido pelo produtor $=\mathrm{R} \$ 0,20 /$ litro). Esse custo elevado da recuperação do anestro onera o custo final da produção de leite, tendo em vista a alta incidência de anestro nos rebanhos brasileiros.
\end{abstract}

Termos para indexação: bovino, ciclicidade ovariana.

\section{FEEDING INTAKE AND COST FOR RECOVERING OVARIAN ACTIVITY IN CROSSBREED DAIRY COWS UNDERGOING ANESTRUS}

\begin{abstract}
This study was carried out to verify feeding intake and cost for recovering ovarian activity in crossbreed cows (Holstein x Zebu). Eighteen non-pregnant cows were used, exhibiting poor body condition, showing cessation of estrus cycle, normal size ovary and no palpated follicles. Twelve animals were maintained indoors and fed to gain weight until recovering ovarian cyclicity. The other six cows, the control group, were fed to maintain weight and to remain in anestrus during the study. Ovarian activity was evaluated by the level of serum progesterone (sampled each seven days), by retal examination of ovaries each twelve days and visual estrus checked three times a day. The recovered ovarian activity required an average feed consumption of $722.4 \mathrm{~kg}$ of dry matter, $50.4 \mathrm{~kg}$ of crude protein and $402.4 \mathrm{~kg}$ of NDT, relative to an average consumption of $2,374.2 \mathrm{~kg}$ of silage and $194.1 \mathrm{~kg}$ of concentrate. Feeding cost plus milking production cost, estimated to increase the calving interval, were estimated as being similar to $1,364.2 \mathrm{~L}$ of milk. The elevated cost to recover anestrus increases the final cost of milk production, due to the high incidence of anestrus in the Brazilian herds.
\end{abstract}

Index terms: bovine, ovarian cyclicity.

\footnotetext{
${ }^{1}$ Aceito para publicação em 15 de maio de 1998.

Parcialmente financiado pelo CNPq.

2 Méd. Vet., D.Sc., Embrapa-Centro Nacional de Pesquisa de Gado de Leite (CNPGL), Rua Eugênio do Nascimento, 610 Bairro Dom Bosco, CEP 36038-330 Juiz de Fora, MG. E-mail: Ademirmf@enpgl.embrapa.br

${ }^{3}$ Méd.Vet., Ph.D., Prof. Titular, Dep. de Zootecnia, Universidade Federal de Viçosa, CEP 36571-000 Viçosa, MG.

${ }^{4}$ Méd. Vet., M.Sc. Bolsista do CNPq.
}

\section{INTRODUÇÃO}

A eficiência reprodutiva dos rebanhos bovinos leiteiros no Brasil é baixa, com intervalo de partos próximo de 20 meses (Ferreira, 1991). Essa informação é confirmada pelos trabalhos de Ferreira et al. (1992), que encontraram apenas $16,2 \%$ de 
concepção até 90 dias pós-parto em 1.674 gestações de 50 rebanhos leiteiros da Zona da Mata de Minas Gerais, com a grande maioria dos animais nãogestantes apresentando condição corporal inferior (magros), característica de subnutrição e ovários inativos.

A alimentação parece ser o fator mais importante no atraso da primeira ovulação pós-parto em bovinos (Karg \& Schallenberger, 1982), com o desempenho reprodutivo sendo bastante dependente dos níveis nutricionais a que são submetidos os animais, responsáveis pela maior parte dos casos de infertilidade no rebanho (Brochart, 1972; Fromageot, 1978; Deletang, 1983; Ferguson, 1994).

A esterilidade ou infertilidade de origem nutricional caracteriza-se por ausência do ciclo estral e do estro, definido como anestro, e sob condição de subnutrição por curto período ou menos severa, por falha na fertilização ou morte embrionária precoce (Roberts, 1971).

A excessiva perda de peso, pós-parto ou no período da seca, acarreta sérios prejuízos, pois a vaca permanece longo tempo em anestro e a concepção não ocorre no período de 78 a 80 dias pós-parto, desejável para um intervalo de partos ideal próximo de 12 meses. Essa situação é mais grave nos trópicos, onde as vacas com maior potencial genético, além de serem afetadas pela ingestão de forragens de baixa qualidade, sofrem influência do clima, como a temperatura elevada, que reduz o consumo de alimento (Lamond, 1970; Martinez et al., 1982; Ferreira et al., 1992).

Baixo nível de energia está associado com reduzida função ovariana (Boyd, 1987), semelhante ao efeito de alguma doença debilitante. $\mathrm{O}$ anestro pode persistir por vários meses, atrasando o cio e a concepção. A correção da alimentação é indispensável para o restabelecimento da atividade ovariana luteal cíclica de vacas magras em anestro ocasionado por subnutrição (Ferreira, 1993).

Embora vários trabalhos mostrem o ganho de peso exigido para a recuperação da atividade ovariana luteal cíclica de vacas ou novilhas em anestro (Hale, 1975; Imakava et al., 1986; Richards et al., 1989; Rhodes et al., 1995), não foram encontradas na literatura informações sobre o consumo de alimentos exigido e o custo para recuperação da AOLC em bovinos com anestro. Em razão da alta incidência do anestro nos rebanhos bovinos leitei- ros do Brasil (Ferreira et al., 1992), informações como essas são importantes para que se possa revelar os prejuízos provocados pela inatividade ovariana.

O objetivo do presente trabalho é avaliar o consumo e custo da alimentação necessária ao restabelecimento da atividade ovariana luteal cíclica em vacas mestiças Holandês x Zebu, não-lactantes, com anestro nutricional.

\section{MATERIAL E MÉTODOS}

O trabalho foi conduzido na Embrapa-Centro Nacional de Pesquisa de Gado de Leite (CNPGL), localizada no município de Coronel Pacheco, Minas Gerais.

Foram usadas 18 vacas adultas mestiças Holandês $x$ Zebu (HZ), não-lactantes, de condição corporal inferior (escore 2 em escala de $1=$ muito magra a $5=$ gorda) e com ausência de atividade ovariana luteal cíclica (AOLC). Os animais constituíram dois grupos que permaneceram em confinamento e receberam alimentação individual: seis animais receberam dieta de mantença para o baixo peso apresentado e constituíram o grupo controle, enquanto 12 animais receberam alimentação para ganho de peso, até que os ovários reiniciassem a AOLC. Aumentou-se o nível nutricional desse grupo gradativamente na fase inicial do experimento, para adaptação da flora ruminal, da seguinte forma: 1 o ao 5 o dia $-10 \mathrm{~kg}$ de silagem de capim-elefante (Pennisetum purpureum, Schum., cv. Napier) + $3 \mathrm{~kg}$ de capim-elefante verde picado, e $1 \mathrm{~kg}$ de feno (Cynodon dactilon, cv. Coast-Cross), divididos em duas porções iguais, oferecidos pela manhã e à tarde; do 60 ao 8 o dia - mesmo volumoso e $250 \mathrm{~g}$ de concentrado/dia; do 9o ao 14o dia - mesmo volumoso e $500 \mathrm{~g}$ de concentrado/dia; do 15 o dia até o 90 o dia - $20 \mathrm{~kg}$ de silagem de capim-elefante e $1.500 \mathrm{~g}$ de concentrado/dia. À medida que a ração era totalmente consumida, aumentava-se a quantidade de silagem oferecida, e a partir do 90 o dia foi oferecido volumoso e $3.000 \mathrm{~g}$ de concentrado/dia. Essa dieta foi mantida até os animais reiniciarem a AOLC.

A silagem de capim-elefante (corte com oito a nove semanas e $1,80 \mathrm{~m}$ de altura) continha $22,9 \%$ de matéria seca, e esta $5,6 \%$ de proteína bruta e $53,0 \%$ de NDT. Os respectivos valores no concentrado foram de 89,$0 ; 11,0 \mathrm{e}$ $64,0 \%$. Os valores do NDT corresponderam à média de diversas análises do material, efetuadas no início, meio e fim do experimento, no laboratório de Nutrição Animal do CNPGL. Água e mistura mineral permaneceram à disposição dos animais.

Os alimentos foram pesados e colocados para os animais, pela manhã, individualmente. Ao entardecer, as sobras, quando existentes, foram pesadas e retiradas do cocho. Dessa maneira, obteve-se a quantidade do alimento consumido por animal/dia. 
A atividade ovariana foi avaliada de três maneiras: exame ginecológico a cada 12 dias, por palpação retal, verificando-se a presença de corpo lúteo nos ovários, observação visual dos sinais de estro três vezes ao dia (manhã, meio-dia e entardecer), e níveis de progesterona no soro sangüíneo $(\geq 1,5 \mathrm{ng} / \mathrm{mL})$ dosados semanalmente.

O preço dos alimentos para estimativa do custo final de recuperação do anestro foi baseado nos valores obtidos no Setor de Sócio-economia do CNPGL, em dezembro de 1995, sendo de R $\$ 17,70$ a tonelada de silagem de capim-elefante e R\$ 0,20 o quilo de concentrado usado. O preço do litro de leite recebido pelo produtor foi avaliado em $\mathrm{R} \$ 0,20$. O custo final total foi convertido em equivalente leite.

Com o objetivo de verificar a influência do ganho de peso/dia no tempo de recuperação da AOLC, foi efetuada análise de correlação de Pearson em relação às duas variáveis.

\section{RESULTADOS E DISCUSSÃO}

Na Tabela 1 é apresentado o consumo de alimentos necessário para a recuperação da atividade ovariana luteal cíclica de vacas em anestro. Os resultados demonstram que a ingestão de nutrientes influencia a atividade ovariana e o aparecimento do estro em vacas mestiças Holandês x Zebu, concordando com as afirmações de Broster (1973), Hale (1975), Topps (1977), Haresign \& Lewis (1979) e Rhodes et al. (1995), e indicam que a infertilidade ocasionada por restrição energética pode ser revertida quando os animais são alimentados para ganho de peso. Vários autores mencionam o ganho de peso necessário para a recuperação da AOLC de vacas em anestro (Hale, 1975; Imakava et al., 1986; Richards et al., 1989; Rhodes et al., 1995), mas não se encontrou menção na literatura sobre o custo e a quantidade de alimentos necessários para tal recuperação.
O período de recuperação da AOLC foi dependente do ganho de peso/dia $(r=0,90)$. Isso mostra que caso se queira reduzir o tempo de recuperação da AOLC nas vacas em anestro, que no presente trabalho foi de 114 dias (ganho de $0,680 \mathrm{~kg} / \mathrm{dia}$ ), é necessário que os animais consumam alimentos de maior valor nutritivo, visando a um maior ganho de peso/dia para mais rápida melhoria da condição corporal.

Em dezembro de 1995, o preço do volumoso usado era de $\mathrm{R} \$ 17,70 /$ tonelada (Resende, 1995) e o do concentrado $\mathrm{R} \$ 0,20 / \mathrm{kg}$. Com base nesses preços, os gastos com a alimentação durante a fase de recuperação da AOLC foram de R $\$ 42,02$ para o volumoso e R $\$ 38,82$ para o concentrado, totalizando $\mathrm{R} \$ 80,84$, equivalente ao valor de 404,2 litros de leite ( $\mathrm{R} \$ 0,20 /$ litro). À despesa com alimentação, entretanto, deve ser acrescida a perda na produção de leite, pois os quase quatro meses (114 dias) exigidos para recuperação da AOLC nas vacas em anestro terá reflexo no prolongamento do intervalo de partos, por igual período, representando uma perda média anual aproximada de $32 \%$ na produção de leite do animal, segundo Ferreira (1991). Considerando-se a produção de 3.000 litros de leite/lactação, a perda estimada na produção de leite em conseqüência do intervalo de partos de 16 meses seria de 960 litros de leite, que, somados aos 404,2 litros gastos com alimentação, totalizaria um prejuízo estimado de 1.364, 2 litros de leite. Dessa maneira as perdas decorrentes do anestro poderiam ser calculadas em função do potencial genético do animal, como se verifica na Tabela 2. Os resultados mostram que não se deve permitir que as vacas emagreçam ao ponto de adquirirem a condição de anestro nutricional devido ao elevado custo de recuperação da AOLC.

TABELA 1. Consumo de alimentos (kg/vaca) necessário para recuperar a atividade ovariana luteal cíclica de vacas mestiças em condição corporal inferior (magras) e em anestro.

\begin{tabular}{lcccc}
\hline Tipo de alimento & Alimento ingerido & Matéria seca & Proteína bruta & NDT \\
\hline Volumoso & & & & \\
Silagem de capim-elefante (cv. Napier) & $2.318,2$ & 530,2 & 29,5 & 281,0 \\
Capim-elefante verde picado & 42,0 & 7,6 & 0,5 & 4,0 \\
Feno ("Coast-Cross") & 14,0 & 11,9 & 1,4 & 6,8 \\
Concentrado & 194,1 & 172,7 & 19,0 & 110,6 \\
\hline Total & - & 722,4 & 50,4 & 402,4 \\
\hline
\end{tabular}


TABELA 2. Custo de recuperação do anestro, em equivalente leite, em vacas com diferentes potenciais de produção (litros/lactação).

\begin{tabular}{cccc}
\hline $\begin{array}{c}\text { Produção de Leite } \\
\text { (kg/vaca/lactação) }\end{array}$ & $\begin{array}{c}\text { Custo da alimentação } \\
\text { (kg de leite) }\end{array}$ & $\begin{array}{c}\text { Perdas na produção } \\
\text { (IP/16 meses }=32 \% \text { perda na produção) }\end{array}$ & $\begin{array}{c}\text { Custo total } \\
\text { (kg de leite) }\end{array}$ \\
\hline 1.000 & 404,2 & 320,0 & 724,0 \\
2.000 & 404,2 & 640,0 & $1.044,0$ \\
3.000 & 404,2 & 960,0 & $1.364,2$ \\
4.000 & 404,2 & $1.280,0$ & $1.684,2$ \\
5.000 & 404,2 & $1.600,0$ & $2.004,2$ \\
\hline
\end{tabular}

As quantidades de NDT e proteína bruta consumidas na recuperação da AOLC representam nutrientes suficientes para a produção de $1.219,4$ e 696,2 litros de leite, respectivamente.

Nos cálculos não foram considerados os prejuízos com a menor taxa de natalidade, visto que os 114 dias de recuperação do anestro correspondem a $40 \%$ do tempo de uma gestação normal (280 dias), nem os gastos com alimentação e perda de produção no período, em geral longo, em que normalmente as vacas leiteiras nos rebanhos nacionais permanecem em anestro, além de 90 dias pós-parto e antes de iniciar o ganho de peso para recuperação da AOLC (Ferreira et al., 1992), correspondente ao intervalo de a e b na Fig. 1.



FIG. 1. Anestro e reinício do ciclo estral depois do parto, em vacas leiteiras: a) período pós-parto a partir do qual a vaca que ainda não manifestou estro é considerada em anestro; b) início do ganho de peso (GP) para recuperação do anestro; c) reinício do ciclo estral (atividade luteal cíclica).
Os animais do grupo controle, permaneceram magros até o final do experimento, apresentando níveis de progesterona no soro sangüíneo menores que $1 \mathrm{ng} / \mathrm{mL}$ em todas as amostras coletadas, confirmando a condição de anestro, contra $2,5 \mathrm{ng} / \mathrm{mL}$ ou mais naquelas que apresentaram AOLC.

\section{CONCLUSÕES}

1. A recuperação da atividade luteal cíclica ovariana (AOLC) em vacas magras, não-lactantes e com anestro nutricional exige grande consumo de alimentos volumosos $(2.374,2 \mathrm{~kg})$ e concentrado $(194,1 \mathrm{~kg})$

2. O custo da alimentação para recuperação da AOLC equivale ao valor de 404,2 litros de leite.

3. Em vacas que produzem 3.000 litros de leite por lactação, o prolongamento do intervalo de partos em quase quatro meses, tempo de recuperação do AOLC, eleva o custo estimado para a 1.364,2 litros de leite.

\section{REFERÊNCIAS}

BOYD, G.W.; KISER, T.E.; COWREY, R.S. Effects of pre partum energy intake on steroid during late gestation and on cow and calf performance. Journal of Animal Science, Champaign, v.64, p. 1703-1709, 1987.

BROCHART, M. Alimentation et fertilité des vaches laitières. L'Elevage Bovin, Paris, v.3, p.53-59, 1972.

BROSTER, H. Liveweight change and fertility in the lactating dairy cow: a review. Veterinary Record, London, v.93, p.417-420, 1973. 
DELETANG, F. Fecondité, la conduite a tenir. L'Elevage Bovin, Paris, n.130, p.44-46, 1983.

FERGUSON, J.D. Production and reproduction in dairy cows. In: SOUTHWEST NUTRITION AND MANAGEMENT CONFERENCE, 1994, Arizona. Proceeding... Arizona: University of Arizona, 1994. p.86-94.

FERREIRA, A. de M. Manejo reprodutivo e sua importância na eficiência da atividade leiteira Coronel Pacheco: Embrapa-CNPGL, 1991. 47p. (Embrapa-CNPGL. Documentos, 46).

FERREIRA, A. de M. Nutrição e atividade ovariana em bovinos: uma revisão. Pesquisa Agropecuária Brasileira, Brasília, v.28, n.9, p.1077-1093, 1993.

FERREIRA, A. de M.; SÁ, W.F. de; VILLAÇA, H. de A.; ASSIS, A.G. de. Diagnóstico da situação produtiva e reprodutiva em rebanhos leiteiros da Zona da MataMG. Pesquisa Agropecuária Brasileira, Brasília, v.27, n.1, p.91-104, 1992.

FROMAGEOT, D. Abord zootéchinique de l'infertilité chez les bovins laitières. 2, les facteurs alimentaires. Recueil Médecine Vétérinare, Paris, v.154, n.3, p.207-213, 1978.

HALE, D.H. Nutrition, hormone and fertility. Rhodesian Agricultural Journal, Salisbury, v.72, n.3, p.69$-74,1975$.

HARESIGN, E.; LEWIS, D. Recent advances in animal nutrition. Boston: Butterworths, 1979. p.107122.

IMAKAVA, K.; DAY, M.L.; GARCIA-WINDER, M.; ZALESKY, D.D.; KITTOK, R.J.; SCHANBACHER, B.D.; KINDER, J.F. Endocrine changes during restoration of estrous cycles following induction of anestrus by restricted nutrient intake in beef heifers. Journal of Animal Science, Champaign, v.63, n.2, p.565-571, 1986.

KARG, H.; SCHALLENBERGER, E. Factors influencing fertility in the post-partum cow. London: Martins Nijhoff Publishers, 1982. 585p.

LAMOND, D.R. The influence of undernutrition on reproduction in the cow. Animal Breeding Abstracts, Wallinford, v.38, n.1, p.359-372, 1970.

MARTINEZ, N.D.; VERDE, O.; FENTON, F.R. Effecto del cambio de peso durante los primeros 90 dias de lactancia sobre la reproduccion. Produción Animal Tropical, Santo Domingo, v.7, p.112-119, 1982.

RESENDE, J.C. Estimativa do custo de produção da silagem de capim-elefante. Coronel Pacheco: Embrapa-CNPGL, 1995.7p

RHODES, F.M.; FITZPATRICK, L.A.; ENTWISTLE, K.W.; DEATH, G. Sequential changes in ovarian follicular dynamics in Bos indicus heifers before and after nutritional anestrus. Journal of Reproduction and Fertility, Cambridge, v.104, p.41-49, 1995.

RICHARDS, M.W.; WETTEMANN, R.P.; SCHOENEMANN, H.M. Nutritional anestrus in beef cows: body weight, body condition, luteinizing hormone in serum and ovarian activity. Journal of Animal Science, Champaign, v.67, p.1520-1526, 1989.

ROBERTS, J. Veterinary obstetrics and genital disease. Ann Arbor: Edwards Brothers, 1971. 776p.

TOPPS, J.H. The relationship between reproduction and undernutrition in beef cattle. World Review of Animal Production, Roma, v.13, n.2, p.43-49, 1977. 